\title{
A Case of Refractory Frontal Sinusitis with a Cutaneous Fistula
}

\author{
Risako Hayashi ${ }^{1)}$ and Takashi Yamatodani2)
}

\begin{abstract}
The frontal sinus is prone to blockade because of the anatomical structure of its excretion path, the frontonasal duct, and it is often difficult to treat frontal sinusitis and frontal sinus cysts. When conservative management is ineffective, frontal sinus operations are performed via nasal endoscopes or an external approach, however, the incidence of postoperative recurrence is high. Obstruction of the front nasal duct causes stagnation of secretions in the frontal sinus, which may result in pressure necrosis of the sinus wall, and rarely, formation of a frontal sinus fistula on the forehead.

Herein, we report a patient with no history of operation or trauma who had refractory frontal sinusitis with a cutaneous fistula. The 60 -year-old male had been diagnosed as having frontal sinusitis and undergone five operations over a period of eight years.
\end{abstract}

Keywords : frontal sinusitis, cutaneous fistula, fat obliteration, omentum

\section{References}

1) Marfatia HK, Muranjan SN, Navalakhe MM, et al. : Persistent frontal fistula. J Postgrad Med 43: 102-103, 1997.

2) Wu VF, Smith TL and Poetker DM : Sinocutaneous fistula secondary to chronic frontal rhinosinusitis: case series and literature review. Ann Otol Rhinol Laryugol 117: 759-763, 2008.

3) Chokkalingam PG, Sachidananda R, Verma S, et al. : Transfistula endoscopic closure of frontocutaneous fistula: a novel approach. Ear Nose Throat J 88: 736-739, 2009.

4) Goodale RL and Montgomery WW : Experiences with the osteoplastic anterior wall approach to the frontal sinus; case histories and recommendations. AMA Arch Otolaryngol 68: 271-283, 1958

5) Goodale RL and Montgomery WW : Anterior osteoplastic frontal sinus operation. Five years' experience. Ann Otol Rhinol Laryngol 70: 860-880, 1961.

6) Goodale RL and Montgomery WW : Technical advances in osteoplastic frontal sinusectomy. Arch Otolaryngol 79: 522529, 1964.

7) Hardy JM and Montgomery WW : Osteoplastic frontal sinusotomy: an analysis of 250 operations. Ann Otol Rhinol
Laryngol 85: 523-532, 1976.

8) Anderson P and Sindwani R : Safety and efficacy of the endoscopic modified Lothrop procedure: a systematic review and meta-analysis. Laryngoscope 119: 1828-1833, 2009.

9) Draf $W$ : Endonasal micro-endoscopic frontal sinus surgery: the Fulda concept. Operative Techniques Otolaryngol Head Neck Surg 2: 234-240, 1991.

10) McLean DH and Buncke HJ Jr : Autotransplant of omentum to a large scalp defect, with microsurgical revascularization. Plast Reconstr Surg 49: 268-274, 1972.

11) Harii $\mathrm{K}$ and Omori $\mathrm{S}$ : Use of the gastroepiploic vessels as recipient or donor vessels in the free transfer of composite flaps by microvascular anastomoses. Plast Reconstr Surg 52: 541-548, 1973.

12) Weber R, Draf W, Keerl R, et al. : Osteoplastic frontal sinus surgery with fat obliteration: technique and long-term results using magnetic resonance imaging in 82 operations. Laryngoscope 110: 1037-1044, 2000.

13）西村俊郎, 山田和宏, 伊藤真人, 他 : 腹腔鏡下採取の大網 による頭頸部再建。日耳鼻会報 107: 658-664, 2004.

14）肾玉 悟：前頭洞炎. 耳鼻 - 頭頸外科 86: 503-508, 2014.
1) Department of Otolaryngology, Iwata City Hospital

2) Department of Otolaryngology, Hamamatsu University School of Medicine
Corresponding Author Address : Risako Hayashi

momiji-hachi@hospital.iwata.shizuoka.jp 

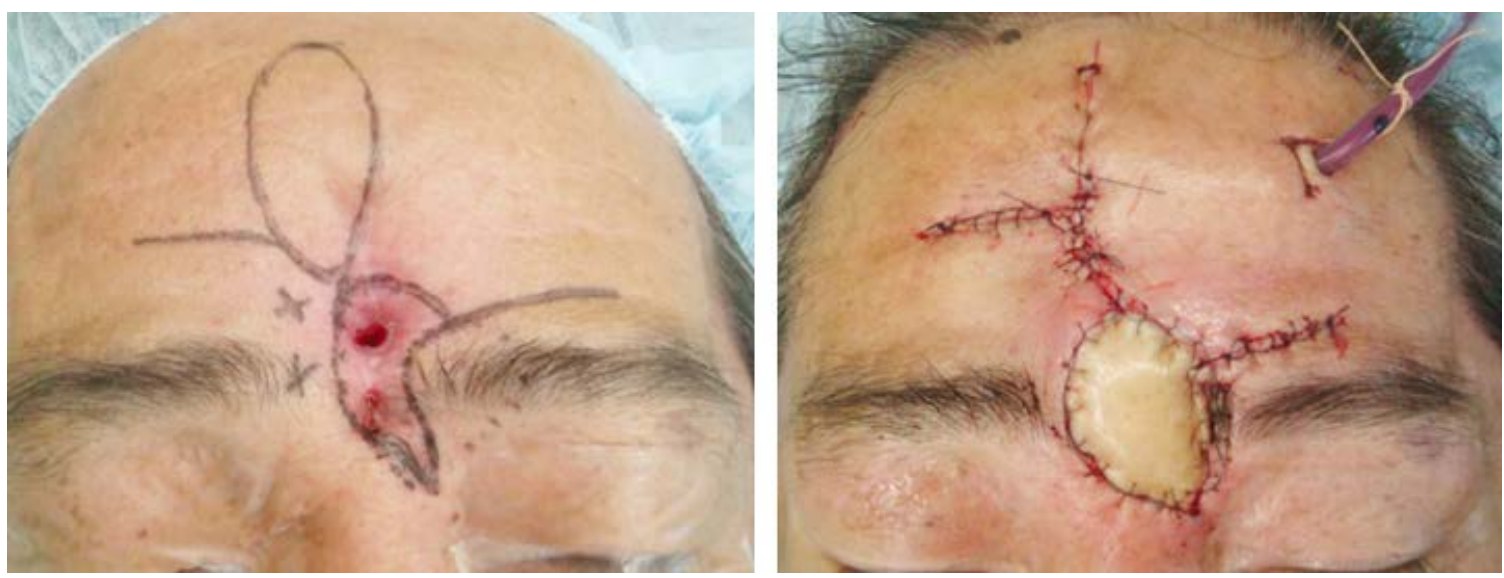

The local frontal flap was designed to cover and close the fistula of the frontal sinus a year eight months after the first visit of the patient to the clinic.

left, preoperative findings, right, postoperative findings

(1)

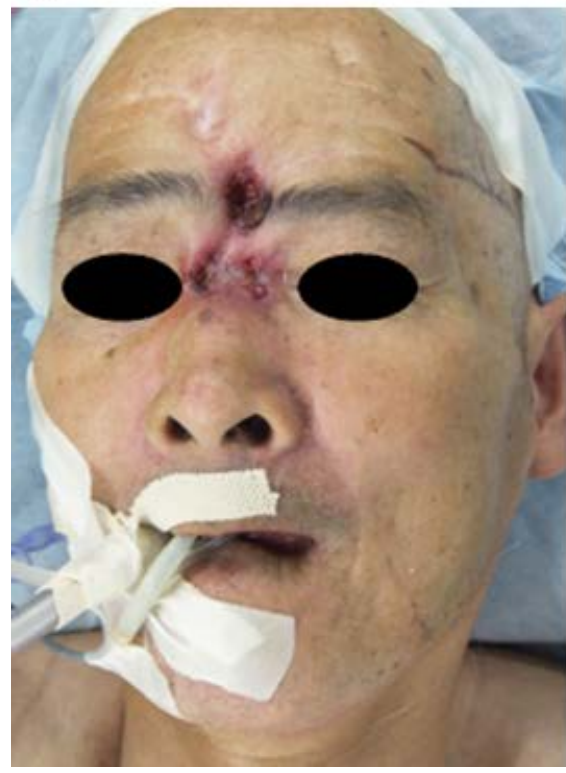

(2)

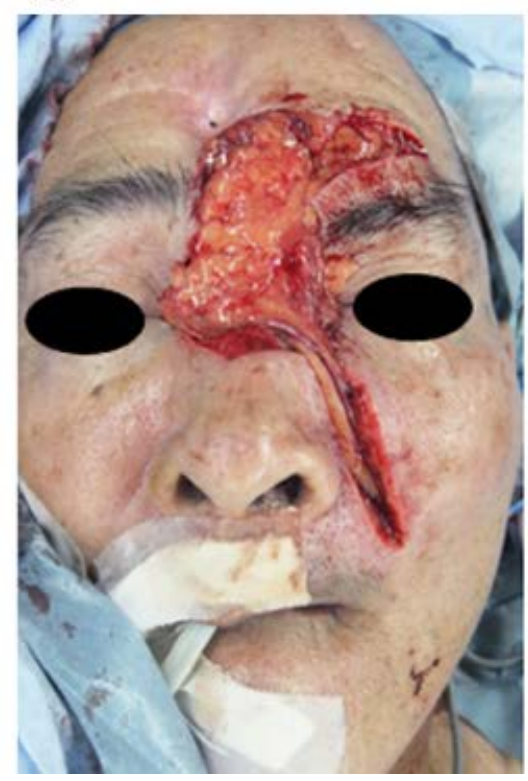

(3)

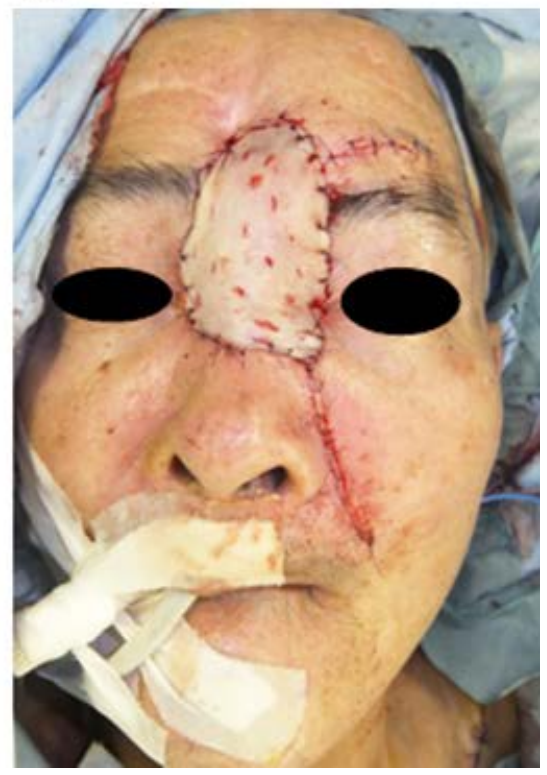

Seven years nine months after the first visit, the frontal sinus was obliterated with the greater omentum, whereas the fistula was covered by skin transplantation.
(1) preoperative findings
(2) the greater omentum was placed in the left frontal sinus.
(3) postoperative findings 